\title{
Curriculum integration of sustainability in engineering education - a national study of programme director perspectives
}

Ola Leifler and Jon-Erik Dahlin

The self-archived postprint version of this journal article is available at Linköping University Institutional Repository (DiVA):

http://urn.kb.se/resolve?urn=urn:nbn:se:liu:diva-166910

N.B.: When citing this work, cite the original publication.

Leifler, O., Dahlin, J., (2020), Curriculum integration of sustainability in engineering education - a national study of programme director perspectives, International Journal of Sustainability in Higher Education. https://doi.org/10.1108/IJSHE-09-2019-0286

Original publication available at:

https://doi.org/10.1108/IJSHE-09-2019-0286

Copyright: Emerald

http://www.emeraldinsight.com/ 


\title{
Curriculum integration of sustainability in engineering education - a national study of programme director perspectives
}

Keywords: attitudes, engineering education, national survey, curriculum integration, faculty support

Ola Leifler

Linköping University, Sweden

ola.leifler@liu.se

Jon-Erik Dahlin

Snowflake Education, Sweden

jon-erik.dahlin@snowflakeeducation.com

Paper submitted 2019-09-28 and revised 2020-04-17

\begin{abstract}
.
Purpose: This study reports on how programme directors address sustainability within engineering education at Swedish universities and engineering colleges.

Design: The study was performed as a survey with follow-up interviews around the following core questions: (i) to what extent do programme directors possess a deep understanding of the subject of sustainable development? (ii) which are the core competencies in sustainable development that programme directors identify as important for their engineering students to acquire during their basic training? (iii) to what extent are those competencies integrated into engineering education today, and (iv) what kind of support do programme directors receive from their department to integrate these competencies into the curriculum?
\end{abstract}

Findings: Programme directors believe that learning for sustainable development is important mainly based on their personal convictions. However, out of 10 potential learning objectives extracted from the literature, only 4-6 are implemented in degree programmes. Learning objectives and activities are not always aligned, as students are required to learn about interdisciplinary collaboration without working with students from other faculties. The programme directors receive some support from the department, but they express a need for additional support. Examples of support that they suggest are faculty training, efficient teaching material, and incorporation of sustainability in the quality assessment instruments for degree programmes.

Originality/value: This study is the first comprehensive, national survey of what programme directors think about sustainability in higher education. Their views are important in the attempt to accelerate the integration of sustainability in higher education curricula.

\section{Introduction}

In recent decades, a revelation has unfolded about the necessity to realign the functioning of most institutions of society - including education - towards a sustainable development. The United Nation's sustainable development goals (SDGs), described in Agenda 2030 (UN General Assembly, 2015), has had a large impact on the global society in providing a common vision of what sustainability means. In higher education, graduates are sometimes 
described as potential change agents (sometimes together with members of faculty). As such, they are being likely to take on professional roles that will put them in power of creating the changes necessary for the SDGs to be fulfilled (Kioupi \& Voulvoulis, 2019).

Higher education is indeed instrumental for fostering the skills needed for graduates to become change agents for sustainable development (Barth, 2015). However, to promote the change needed in society, higher education institutions (HEIs) themselves will need to change even quicker than society as a whole. It is, therefore, critical to understand the drivers for such change. Those drivers are on the one hand attitudes towards the integration of sustainability among programme directors, and on the other hand factors such as regulations, standards, and faculty goals.

The majority of previous research of how sustainability is integrated into curricula have involved case studies (Weiss and Barth, 2019). Those provide a descriptive account of this process of change at only a few selected HEIs at a time. While providing important examples and inspiration for other HEIs, case studies, however, have limited value for understanding the generalised factors that influence the process of integrating of sustainability in curricula. In a few studies, the difficulties involved in integrating sustainability in curricula have been addressed through survey studies (e.g. Leal Filho et al, 2017; Lozano et al, 2017). Those studies target sustainability-focused managers or researchers. They cover broad areas of integration approaches and factors that influence the outcome related to both education, research, campus operations and outreach. Unfortunately, those studies lack in detail and specificity in their analysis of key stakeholders such as those responsible for designing curricula and degree programme learning goals - such as programme directors.

In this study, the authors have instead opted for a different approach. This study reports on the attitudes and perceptions about sustainable development of all degree programme directors in engineering education in Sweden. For this particular branch of education (i.e. engineering) and national setting (i.e. Sweden), centralised regulation and efforts have been in place for more than a decade to enforce the integration of sustainability in curricula. The authors are interested in understanding whether there are common factors that determine programme directors' attitudes towards, and ability to integrate sustainability. They submit that the findings from this study will be of interest also in other branches of education and in other national settings.

Engineering programmes are subject to well-established accreditation programmes such as EUR-ACE (ENAEE, 2008) in Europe and ABET (ABET, 2010) in North America. Both EUR-ACE and ABET include requirements for engineers to contribute to a sustainable development. The following are examples of requirements from both accreditation and legal requirements regarding integrating sustainability in engineering education.

A graduate should be able to [emphasis added]:

- "design a system, component, or process to meet desired needs within realistic constraints such as economic, environmental, social, political, ethical, health and safety, manufacturability, and sustainability" (ABET, 2010).

- "[demonstrate] awareness of the health, safety and legal issues and responsibilities of engineering practice, the impact of engineering solutions in a societal and environmental context, and commit to professional ethics, responsibilities and norms of engineering practice" (ENAEE, 2008). 
- "demonstrate [an] ability to design and develop products, processes and systems with consideration of human prerequisites and needs and the society's goals for economically, socially and ecologically sustainable development." (Svensk författningssamling, 2005).

Together, these standards and regulations provide ample external motivation for degree programme directors to integrate sustainability in their programme goals and curricula. Also, engineering as a practice and profession is intrinsically concerned with solving problems, including the pressing challenges facing humanity. Therefore, it is of general interest for higher education management within engineering to understand which factors that contribute to attitudes and perceptions among programme directors that would support such integration of sustainability in programme goals and curricula.

The integration of sustainability in engineering curricula generally follow one of two approaches: (i) to focus on analytical approaches of the impacts of technology, such as lifecycle assessments of products; or, (ii) trying to achieve positive system transformation through management and innovation related to technology and social change (Mulder, 2017). However, as argued by Mulder (2017), these different approaches may ultimately miss the point, that all engineering education will have to be reoriented towards addressing global challenges. Otherwise, they may lose their legitimacy for societal stakeholders. Another way to describe possible approaches to integrating sustainability in curricula, is to start with strategic sustainability competencies, described by Segalàs et al (2009) and Wiek et al (2011) among others. In those papers, the authors stipulate learning goals related to a general awareness of global challenges and trends, the ability to deal with conflicting norms and values around sustainability challenges, the ability to think in terms of general systems with feedback loops and how to collaborate across disciplinary boundaries. The development towards integrating those key competencies generally follow development trajectories which start with individual teacher activities and progress through networking among educators. Those would in turn influence policy instruments, which then will affect both teaching and research more broadly (Dlouhá et al, 2017). In both research and teaching, successful sustainability initiatives are characterized by strong inter-disciplinary activities, even ones transgressing disciplinary boundaries to reach at solutions out of reach from any one discipline (Brandt et al, 2013; Lang et al, 2012). Trans-disciplinary thinking is key for the development of strategic competencies. In order to facilitate trans-disciplinary thinking to form, it is necessary to form networks among educators and researchers who realize the needs for collaboration (e.g. Dlouhá et al, 2017).

\section{Engineering education for a sustainable society}

Engineers will play a central role on the path society takes towards long-term sustainability. They are central in addressing societal challenges involving new technical solutions, but will also need to adopt a broader view on how technical systems affect social and economic dimensions. They will also need to better address how we can work meaningfully to counter negative global trends such as destructive climate change, environmental degradation, oppression and inequality.

In contrast to traditional requirements in engineering curricula, learning for a sustainable future does not mean that students need to learn how to apply known solutions to well-defined problems. Sustainability challenges are notorious for being difficult, complex, crossdisciplinary problems with no obvious, optimal solution. Strategic sustainability competencies 
are critical for effectively managing such problems but are often underrepresented in curricula (e.g. Segalàs et al, 2009). Although frameworks for key competencies in sustainability have been proposed (Wiek, Withycombe, \& Redman, 2011), there is still no universal consensus on what specific sustainability-related competencies should be included in an engineering curriculum (Mulder, 2017).

\section{Common issues in transforming engineering education for a sustainable future}

Engineering education has long been characterized by a strong, technical and mathematical foundation for problem-solving. In as much as engineers have been instrumental in creating the technical underpinnings of modern society, they have also been a symptom of the compartmentalization of knowledge. This has led to the development of ecologically, socially and economically unsustainable systems.

It has been argued that engineering education needs to transcend disciplinary boundaries, and shift focus from optimizing current processes and systems to facilitating system changes (Ashford, 2004). This may prove difficult. Compare, for example, how specific competencies relating to the analysis of product life cycles have developed within the domains of engineering education and how those have proven resilient to influences from more policyoriented research on innovation and systems change. In effect, two parallel paradigms for addressing sustainability seem to have emerged over the last decades. One paradigm is concerned with the optimization of resource use in current socio-technical systems and employs methods like lifecycle assessment and energy technologies. The other paradigm focuses on changing the systems themselves in more fundamental ways (Mulder, 2017).

Transforming engineering education is in many ways similar to transforming other societal systems. There are sources of inertia in large organisations, barriers to communication between different disciplines and departments as well as a lack of incentives for fundamental change. Some of these barriers are social, cultural and economic. Barriers may also be practical and physical, eg. that staff with different academic backgrounds are often physically located at different parts of the campus premises. Incentives and reward structures can create disincentives for working across disciplinary boundaries, which can be an important issue to overcome when transforming higher education institutions to promote learning for sustainable development (O'Brien et al, 2013). Another important factor for meaningful curriculum transformation is the training of academic staff, and lack thereof may also become a barrier (Barth and Rieckmann, 2012).

Frameworks for assessing sustainability aspects in higher education traditionally focused on the governance of campus facilities rather than the collaboration between educators, researchers and the surrounding community (Yarime \& Tanaka, 2012). However, there are frameworks that specifically assess the integration of sustainability in higher education (e.g. Roorda \& Martens, 2008) and national frameworks for assessing sustainability integration (e.g. Dlouhá et al, 2017). In the studies by Dlouhá et al (2017) and Leal Filho et al (2017), common issues that need to be managed in the transformation of education are the need for management support in general, lack of awareness and competence among staff, the needs for supporting cross-disciplinary approaches and the needs for innovative and engaging teaching methods. One response to these issues has been to include demands through accreditation bodies or national regulations (see Section 1). However, the inclusions of such demands through regulatory bodies is not necessarily the most effective means by which to stimulate change, if the feedback mechanisms affecting faculty members are not aligned with those higher goals. Faculty members typically have incentives to strive for disciplinary excellence 
and to include their research in their respective degree programmes. This may or may not be well aligned with fulfilling demands of cross-disciplinary approaches to teaching, adopting engaging teaching methods and admitting a lack of knowledge of sustainability fundamentals. Therefore, it is of general interest to study the outcome of one set of such legal requirements, namely those in Sweden related to engineering degree programmes.

\subsection{The effects of legal requirements for integrating sustainability in Sweden}

National frameworks may come in different forms, from charters to common learning goals or quality assessment frameworks. At the beginning of the United Nations Decade of Education for Sustainable Development, Sweden adopted a new law that stipulates all universities shall act to promote sustainable development in society. The paragraph (Swedish Higher Education Act 1992:1434, Chapter 1, §5) states this is a general requirement for higher education and research.

In addition, the ordinance documents for Swedish Higher Education (Svensk författningssamling, 2006), stipulate expected learning outcomes for all degrees awarded at HEIs. For some of the nationally recognized degrees, there are specific requirements related to competencies associated with sustainable development as exemplified in Section 1. For engineering graduates, that means they should "demonstrate an ability to design products, processes and systems with respect to people's abilities and needs, and society's needs for an economically, socially and environmentally sustainable development" and be able to "show appreciation of the affordances and limitations of technology, the role of technology in society, and responsibilities for the use of technology, regarding social, economic, environmental and ergonomic aspects". Together with the more general Higher Education Act (Svensk författningssamling, 2005), which stipulates how higher education in Sweden is organized, these two pieces of legislation serve as a guide for all national degree programmes and is used in national evaluations.

Despite legal requirements, a 2017 national evaluation survey by the Swedish Higher Education Authority (UKÄ) found that only $25 \%$ of HEIs had a well-established process for integrating sustainability in their programmes and courses. Three main areas were assessed: management, resources and performance. Management concerned goals and internal reviews; resources concerned whether specific resources such as teacher training are given to implement goals; and, performance concerned curricula and degrees specifically designed with sustainability in mind. Among the three areas, management was the least well-developed overall. Two thirds of the HEIs had no coherent mechanisms for assessing whether they could achieve the legal requirements related to sustainability. Although lawmakers have made it a requirement for engineering departments to adapt their curricula accordingly, few HEIs work systematically to integrate sustainability-related competencies. To understand why, the researchers examined the attitudes and perceptions about sustainable development among programme directors, as well as external incentives. Programme directors are important stakeholders as they are directly responsible for the content and development of the programmes, even if formal decisions often are made at the faculty level. They receive departmental or faculty resources to implement changes; they try to align the learning objectives of the degree programme with the national requirements for the degrees that they issue; they often have a direct connection to research related to the degree programmes; and they have contact with most teaching staff. Therefore, it is important to understand 
programme directors and their situation if we wish to implement more profound changes within higher education curricula, and ensure that students graduate with the strategic competencies that allow them to contribute to a sustainable development.

\subsection{Study design}

In order to better understand how programme directors reason about the integration of sustainability in their degree programmes, an online survey was designed for this purpose. Our main strategy was to examine national quantitative trends on perceptions, motivations and support. To assess whether respondents understood the questions, the survey included options to provide free-text explanations to most questions, as a way to capture if they had misunderstood the questions. In order to obtain a high response rate, the online forms were combined with targeted reminders through e-mail and phone calls for those who had not answered within the allocated time period, and clarifying interviews for respondents whose responses were hard to interpret.

Most questions were designed for quantitative analyses, to describe single variables such as their motivations for integrating sustainability in education. However, the questions on learning goals and activities were designed as validation. Here, the aim was to assess whether there were explicit goals on being able to collaborate in multi-disciplinary teams, and if that coincided with learning activities performed in such truly multi-disciplinary teams across faculty boundaries.

The authors first crafted a set of questions that were reviewed by several programme directors from two different HEIs. Based on the revised set of questions, HEI websites were scanned for current contact information and the information was manually validated so that all such information was correct before the online survey was prepare the online survey.

\subsection{Delimitations}

Although engineering degree programmes in several countries are subject to similar degree requirements, this study focuses on the situation in Sweden but strives for a broad outreach among programme directors in the sector. A limitation to this approach is that cultural or societal aspects specific to Sweden may influence our results and their general applicability.

\section{Method}

Based on the literature of current approaches and obstacles, this study addresses how programme directors of all engineering degree programmes in Sweden consider their work, incentives and challenges related to sustainability teaching. An online survey was submitted to all programme directors of engineering in Sweden $(\mathrm{N}=244)$ proceeded by short follow-up interviews of their survey answers.

\section{Respondents}

The respondents represent most of the traditional engineering fields, as shown in Table 1 . The total number of respondents was 89 (34\% response rate). At one university, each respondent was responsible for more than one programme. However, this was an exception to the general rule of 1-1 correspondence between programme directors and degree programmes.

Swedish engineering education generally follows a model where students are admitted either to a three-year Bachelor's programme, or directly admitted to a five-year Master's programme. The study explores whether there are meaningful differences between the groups 
depending on the length and level of the degree programmes. Therefore, the survey results for the Bachelor's level directors and Master's level directors are reported separately.

Table 1: Number of survey respondents from different degree programmes.

\begin{tabular}{lrr}
\hline Category & $\begin{array}{r}\text { Bachelors in } \\
\text { Engineering (N = 57) }\end{array}$ & $\begin{array}{r}\text { Masters in } \\
\text { Engineering (N=32) }\end{array}$ \\
\hline Computer Science/Electrical Engineering & 11 & 4 \\
Civil Engineering/Construction/Architecture & 13 & 4 \\
Mechanical Engineering/Product design & 12 & 5 \\
Energy Systems & 10 & 6 \\
Chemical Engineering/Biotech & 2 & 5 \\
Engineering, Economy and Management & 3 & 4 \\
Others & 6 & 4 \\
\hline
\end{tabular}

\section{Survey}

The survey included a combination of multiple-choice questions, Likert-scale ratings and free-text responses. All questions, except in the first Section, included free-text responses.

Four themes were addressed. Firstly, respondents were asked about their domain background, their understanding of the concept of sustainability and their motivations in integrating sustainability into their curricula. Their general experience as programme directors was also noted.

Secondly, they were asked whether engineers from their degree programme would be able to contribute to any of the 17 Agenda 2030 goals (UN General Assembly, 2015). An option for a free-text response was also provided, where respondents reported on how they regard the relationship between the learning outcomes of their programme and the challenges listed as part of the sustainable development goals.

Thirdly, they were asked which particular learning outcomes they associated with being able to address sustainability challenges. Here, the key competencies listed in the study by Segalàs et al (2009) were used as a reference point and the respondents reported on whether any of the main competence areas described in that paper were explicitly integrated in their own programme. They were also asked about the learning progression within the field of sustainability through their programme and how it was designed to address the expected learning outcomes.

Fourthly, they were asked whether they could identify any particular challenges or needs for support, related to the competencies, sustainability definitions, perceived relevance, or in relation to the current curriculum.

To ensure a high response rate, multiple e-mail reminders were sent and programme directors who had not responded were encouraged by phone calls to participate. This way, the study obtained responses not only from the most motivated participants but also from less motivated ones.

\section{Interviews}

As a follow-up to the survey, participants were asked to elaborate on their responses through short interviews. Those who provided answers that deviated from the norm of the responses in 
several of the categories were selected for the interviews, to verify that they had not misunderstood the questions. Four respondents provided short interviews in this way after they had provided their answers in the online survey. Follow-up questions related specifically to their free-text responses. In this way, more in-depth information was collected on specific points that were found to be especially interesting. For example, if respondents had answered in a manner that deviated significantly from the majority, or if they had chosen to agree or disagree strongly with certain options, they were selected for follow-up interviews to elaborate on those issues in particular. The interview questions, therefore, concerned the type of progression that they had or wished to have through their degree programmes, and what support they would like from the department to incorporate sustainability issues in the curriculum.

\section{Results}

In this Section, core findings are presented.

\section{Background knowledge and motivation}

As an introductory question, respondents were asked what they associated with the term sustainable development. The most frequent association was the definition in the Brundtland report, that a sustainable development is the kind of development that "meets the needs of the present without compromising the ability of future generations to meet their own needs" (Brundtland, 1987) (Table 2). Significantly fewer associated the term with the preservation of biodiversity, assessing the triple bottom line of businesses or striving for the Agenda 2030 goals. The associated free-text responses also indicate that a sustainable development focusing on human needs dominates the respondents' world view and especially those needs that can be directly addressed through engineering efforts, thus implying they adopt an anthropocentric or materialistic view when considering sustainability. As an example, some respondents associated sustainability with "using energy and resources effectively" and "the judicious use of immaterial resources such as ownership, power and democracy". However, there were also responses that indicated a more ecocentric perspective, such as "the total effect on the environment by mankind must simply be reduced compared to today." It is difficult to tell whether these responses alone indicate that programme directors subscribe to the notion of the so-called weak sustainability (that the total value of human and natural capital should not decrease over time, and where the loss of natural resources can be compensated) as compared to strong sustainability (a definition of sustainability where the degradation of natural resources and ecosystems cannot be compensated) (Neumayer, 2003). There was only one major difference between the groups in that a lower rate of the Bachelor's degree respondents associated sustainability with assessing the triple bottom line for businesses.

Table 2: Responses to "What do you associate with the concept 'sustainable development'?". Percentage of respondents associating SD to each concept.

\begin{tabular}{lcr}
\hline Definition & BSc & MSc \\
\hline $\begin{array}{l}\text { Meeting the needs of the present without compromising the } \\
\text { ability of future generations to meet their own needs }\end{array}$ & 88 & 86 \\
Long term management of human and natural resources & 73 & 83 \\
Conserving biological diversity & 52 & 57 \\
Environmental, social and economic systems are in & 73 & 71
\end{tabular}

balance 


$\begin{aligned} & \text { Striving for fulfilment of the UN's Sustainable } \\ & \text { Development Goals of Agenda } 2030\end{aligned}$
$\begin{aligned} & \text { Business should be evaluated against social, economic } \\ & \text { and environmental factors (triple bottom line) }\end{aligned}$

Apart from their associations, their personal motivations were examined. Respondents were asked about what motivated them and were given six options, shown in Table 3, rated on a 4point Likert scale. The options were chosen to represent the most common driving factors of change. The legal requirements related to the national audit are listed in Section 1. Apart from this, the auditing agency UKÄ requires all degree programmes to include students and societal stakeholders (graduates' future employers) in their quality assurance processes. Students' attitudes are generally important through student evaluations of courses and degree programmes, and employers can provide valuable input about competence needs that they are facing. In addition, programme directors may have their own internal motivations for integrating sustainability. The study aimed to uncover the relative strengths of these different factors as perceived by the programme managers.

In general, the Master's programme directors were more driven by external factors, but their intrinsic motivation (factor 4) was very similar, in that they seemed to share the view that sustainable development is overall very important to them.

Table 3: Motivating factors for working to integrate sustainability into degree programme curricula. Replies provided on a scale 1-4, where 1 means they were not motivated by the factor, and 4 means highly motivated by the factor.

\begin{tabular}{lll}
\hline Motivating factor & BSc & MSc \\
\hline 1. Legal requirements in the Higher Education ordinance & 2.8 & 3.16 \\
2. General legal requirements for higher education & 2.27 & 2.77 \\
3. National review 2017 & 1.91 & 2.57 \\
$\begin{array}{l}\text { 4. Own conviction of importance of working for a sustainable } \\
\text { development }\end{array}$ & 3.70 & 3.73 \\
5. Students' attitudes and wishes & & 3.39 \\
6. Employers' attitudes and wishes & 2.86 & 3.06 \\
\hline
\end{tabular}

\section{Contributions to Sustainable Development Goals}

In the UKÄ national evaluation of degree programmes, Agenda 2030 was suggested as a framework for more concrete definitions of sustainability (UKÄ, 2017). Therefore, it was interesting to know to what extent programme directors were actively using the goals in Agenda 2030 in programme curriculum design.

Only slightly more than half of the programme directors associated the concept of sustainable development with striving for the 17 Sustainable Development Goals (SDGs) of Agenda 2030 (Table 2). When asked specifically which, if any, of the goals that students could be expected to contribute to after their studies, they mostly indicated goals that relate to resource management, reflecting their earlier response of what they associated with the concept of sustainable development. In Table 4, it is clear that the vast majority of the respondents recognized Goal 7 ("To provide access to reliable, sustainable and modern energy sources at a reasonable cost") as a goal their students could address. Socially oriented goals were the least relevant, as only $12-20 \%$ of the respondents indicated that the goals concerning reductions of inequality (Goal 10), promoting peaceful, inclusive societies (Goal 16) and revitalising global 
partnerships (Goal 17) were relevant for their students. As a general tendency, programme directors view goals that are oriented towards efficient resource management as more relevant to engineering students.

Table 4: Response to "Which, if any, of the 17 SDGs would an engineer from your degree programme have competencies to address?". Percentage of respondents agreeing a graduate would be able to contribute to each SDG, for BSc/MSc level programmes.

\begin{tabular}{llllllllllllllllll}
\hline SDG & $\mathbf{1}$ & $\mathbf{2}$ & $\mathbf{3}$ & $\mathbf{4}$ & $\mathbf{5}$ & $\mathbf{6}$ & $\mathbf{7}$ & $\mathbf{8}$ & $\mathbf{9}$ & $\mathbf{1 0}$ & $\mathbf{1 1}$ & $\mathbf{1 2}$ & $\mathbf{1 3}$ & $\mathbf{1 4}$ & $\mathbf{1 5}$ & $\mathbf{1 6}$ & $\mathbf{1 7}$ \\
\hline BSc & 11 & 21 & 29 & 43 & 32 & 48 & 64 & 50 & 73 & 18 & 48 & 70 & 38 & 16 & 27 & 23 & 14 \\
MSc & 29 & 37 & 40 & 46 & 40 & 57 & 83 & 54 & 71 & 26 & 31 & 54 & 71 & 26 & 37 & 29 & 17 \\
\hline
\end{tabular}

The free text responses also indicate that the SDGs, and global challenges in general, do not seem to have been used as guiding principles for the development of degree programmes to any significant extent. One respondent writes that "it is hard to tell whether there is a specific connection between courses and the Agenda 2030 goals", and another indicates that, as a side effect of the general training of engineers in optimization and problem solving, they will help contribute to a more sustainable society: "in automatic control, good regulators reduce emissions and require less raw materials." Many respondents think that engineers, merely by being problem-solvers, are automatically equipped with relevant competencies to address sustainability challenges. A difference between the two groups is that the Master's level programme directors believed a wider range of societal problems could be addressed by their graduates.

\section{Learning objectives}

It was investigated whether the respondents reported that their programmes' learning objectives related to the strategic competencies for sustainable development. The list of potential key competencies was based on the ones identified by Segalàs et al (2009). This question also investigated whether learning objectives related to sustainability were understood in the same way as they are described in the literature. The 10 key competencies listed in Table 5 were given as a list to choose from, and programme directors were asked whether students would be able to utilise them after acquiring their degree. Four learning objectives $(1,3,4$ and 7$)$ were included in both groups. The degree to which other goals were important differed, with the largest difference occurring between the two groups being around the normative competence (goal 10).

Table 5: Percentage of respondents who claim that the following learning objectives are covered in their programmes.

\begin{tabular}{|c|c|c|}
\hline Students should be able to: & BSc & MSc \\
\hline 1. Understand societal challenges related to the need for sustainable development & 64 & 69 \\
\hline $\begin{array}{l}\text { 2. Understand the causes of unsustainable societal systems, especially in relation to } \\
\text { technology }\end{array}$ & 48 & 63 \\
\hline $\begin{array}{l}\text { 3. Understand the interface between their own professional area, economic, ecological } \\
\text { and social systems }\end{array}$ & 55 & 57 \\
\hline $\begin{array}{l}\text { 4. Have constructive dialogues with people from different disciplinary backgrounds } \\
\text { when addressing problems }\end{array}$ & 70 & 66 \\
\hline 5. Switch temporal, cultural and geographic perspectives when addressing problems & 18 & 31 \\
\hline $\begin{array}{l}\text { 6. Identify larger socio-technical systems, their components, boundaries, and cause- } \\
\text { effect relationships }\end{array}$ & 13 & 29 \\
\hline $\begin{array}{l}\text { 7. Reflect on their roles as engineers and the responsibility of an engineer in working } \\
\text { towards a sustainable development }\end{array}$ & 84 & 83 \\
\hline
\end{tabular}


8. Participate in and facilitate inclusive, democratic problem-solving processes

9. Willingness to contribute to changes in societal systems and personal behaviour to contribute to a long-term sustainable development

10. Have a well-developed ability for ethical judgments related to personal and professional activities

\section{Progression of learning objectives}

The respondents were asked about how the progression of learning objectives in sustainable development is organised within their programmes in terms of the stated competence goals. As seen in Table 6, there is a clear tendency towards the adoption of introductory courses in sustainable development. One interpretation of the answers is that the adoption of introductory courses is considered the easiest route to achieve at least some sustainability education in the programme, considering that programme directors, in general, regard the integration and progression of sustainable development as a challenging undertaking. It was possible to examine several options here. Bachelor's programmes seem to have a higher degree of integration in existing courses compared to Master's programmes, and fewer course activities that are not assessed.

Table 6: The organisation of progression for students with respect to sustainability competencies, in percentage of respondents.

\begin{tabular}{lcr}
\hline Progression & BSc & MSc \\
\hline $\begin{array}{l}\text { 1. Introductory courses in sustainable development } \\
\text { 2. Through assessed subsections in courses in every }\end{array}$ & 63 \\
programme year & 32 & 17 \\
$\begin{array}{l}\text { 3. Through assessed subparts in at least three } \\
\text { mandatory courses throughout the programme }\end{array}$ & 36 \\
$\begin{array}{l}\text { 4. Through assessed subparts in at least one } \\
\text { mandatory course throughout the programme }\end{array}$ \\
$\begin{array}{l}\text { 5. Through introductory, non-assessed course } \\
\text { activities }\end{array}$ \\
\hline
\end{tabular}

It can be noted that several of the alternatives were not exclusive, which becomes obvious when summarizing the results from Options 2-5 for the two groups.

It has been stressed by Enelund (2015) and others that the integration of education for sustainable development with progression through the programme should emphasise a deep connection between sustainability and the core engineering skills of the programme. Such an approach should emphasise a professional outlook, an integration of general engineering skills, and authentic engineering experiences with a focus on a holistic view of products and systems. Merely introducing sustainability as a concept does little in terms of integration, and just working with sustainability issues once or twice within the space of a whole programme is not enough to achieve any progression. A programme map, such as those suggested in the CDIO syllabus (Armstrong 2007), may constitute a useful tool for mapping the progression of sustainability though the programme. The method described by Sheehan (2015) may be used as a reference for acquiring true integration of sustainability issues in a way that is relevant for the courses designated for contributing to the progression. The objective would be to achieve such integration while ensuring that sustainable development is treated as a subject on 
its own, and that a progression of knowledge, skills and proficiency is achieved in sustainable development as well as within the subjects that deliver the context for relevance.

\section{Learning activities that are currently integrated in programmes}

The respondents were asked which specific learning activities they use to achieve the sustainability objectives in Table 5. As seen in Table 7, traditional learning activities such as lectures, writing assignments and project work are predominant. Even though those indeed can be delivered in a non-traditional manner, the free text answers confirm that most teaching methods that are actually used are traditional classroom teaching. In contrast, learning methods that are intrinsically based on active learning pedagogy and contextualised learning, such as laboratory exercises, educational games and external projects, are much more sparsely represented. However, seminars and internal projects seem to represent a common type of active learning activity among the respondents. No major differences between the two subsamples was seen in this respect.

Table 7: Learning activities that students engage in to achieve sustainability learning objectives, percentage of respondents.

\begin{tabular}{llr}
\hline Learning activity & BSc & MSc \\
\hline Lectures & & 94 \\
Lab sessions & 96 & 29 \\
Written assignments & 32 & 74 \\
Seminar discussions & 73 & 77 \\
Games & 73 & 26 \\
Internal projects & 11 & 77 \\
\hline Projects with external partners & 70 & 40 \\
\hline
\end{tabular}

As seen in Table 8, student projects with participation by non-academic partners is relatively unusual. This result is interesting especially because of the intrinsically multidisciplinary aspects of sustainable development as a subject, and since stakeholder-involvement is often argued for as an important strategy in real-life strategies for sustainable development. Projects are predominantly carried out in groups of 3-8 students from the same background, although most directors stated that their students were supposed to learn how to collaborate with people from different disciplinary backgrounds (Table 5, option 4).

Table 8: Project types, by the number and type of students participating, in percentage of respondents.

\begin{tabular}{lrr}
\hline Students in projects & BSc & MSc \\
\hline Single or pairs & 63 & 46 \\
Groups of 3-8 from same background & 84 & 74 \\
Groups of more than 8 from same degree programme & 2 & 3 \\
Students from different degree programmes & 20 & 43 \\
Students from different faculties & 2 & 6 \\
\hline
\end{tabular}

\section{Potential challenges}

In Table 9, potential challenges associated with the introduction of a progression scheme for learning objectives in sustainable development are addressed. The most obvious challenge for programme directors is the allocation of academic credits for new content, which is considered a prerequisite for adding material into courses relating to sustainability. Competence among faculty (or lack thereof) in teaching for sustainable development is also 
stated as an important challenge. These aspects may relate to the strong disciplinary aspect of the natural science and engineering traditions. However, most of the programme directors perceive a strong connection between sustainability and the core subject in the study.

Table 9: Importance of challenges for integration of sustainability in curriculum. Replies provided on a scale 1-4, where 1 means not important, 4 means very important.

\begin{tabular}{lcc}
\hline & BSc & MSc \\
\hline Unclear definitions & 2.28 & 2.33 \\
Crowded curriculum & 2.52 & 2.77 \\
Programme subject does not relate to & 2.04 & 1.60 \\
sustainability & & \\
Lack of competence & 2.50 & 2.48 \\
\hline
\end{tabular}

\section{Support}

The final questions respondents were asked focused on the support they receive and would like to receive from their department. There is a great discrepancy between the support received and support requested, as seen in Table 10. Respondents consistently rate the significance of each type of support higher than the degree to which they receive it at the moment. It is clear that the universities' goals were among the most important instruments for directing change. However, during one of the interviews, one of the subjects explained that even if there are goals, they will have to be made specific enough to be relevant: "you know that all degree programmes are supposed to work with sustainability in one way or the other but not how."

Table 10: Assessment of support for integrating sustainability. Ratings were given in the interval 1-4, where 1 meant poor support, or low importance, and 4 meant strong support or high importance.

\begin{tabular}{lcc}
\hline $\begin{array}{l}\text { Do you receive support for integrating } \\
\text { sustainability into your curriculum (and how } \\
\text { important do you think each kind of support is)? }\end{array}$ & BSc & MSc \\
\hline Faculty training & $2.09(3.19)$ & $2.17(3.24)$ \\
University/department goals & $2.43(2.56)$ & $2.97(2.87)$ \\
\hline Teaching materials & $1.63(2.73)$ & $1.93(2.71)$ \\
Economic support from department & $1.48(2.41)$ & $1.73(2.53)$ \\
$\begin{array}{l}\text { Integration of sustainability in quality assessment } \\
\text { framework }\end{array}$ & $2.09(2.62)$ & $2.53(2.66)$ \\
\hline
\end{tabular}

\section{Discussion}

It should be noted that there is a risk that the sample may not be statistically representative. However, in the end, significant effort was put into recruiting respondents and a very high response rate was actually achieved (34\%). Therefore, the authors are confident that any deviation would not potentially shift the general conclusions of this study and thus, no specific compensatory factors were weighted into the analysis to compensate for this risk.

Among the results, there are certainly both some that are expected and indeed a few that are surprises. The observation that most programme directors follow an anthropocentric line of thinking along with a weak-sustainability notion were no surprises (Section 4.1). For example, 
the inclination to subscribe to a view where natural resources must be managed and have no inherent value aside from fulfilling human desires, corresponds to the "guarding" metaphor expressed by engineering tutors in a study by Cotton et al (2007). Furthermore, the tendency to quote Sustainable Development Goals nr 7, 9 and 12 can hardly be considered anything but expected (Section 4.2). However, it is interesting to note the difference between BSc and MSc directors regarding SDG nr 13 ("Climate action"), where the former show little confidence their alumni will contribute to that goal whereas the latter state a strong conviction their alumni will be well-equipped. Perhaps this is a reflection of MSc programmes generally reaching a higher level in complex systems thinking, which could be regarded a prerequisite to 'solving' climate change. The least frequent learning goals in engineering degree programmes seem to be those related to democratic problem-solving processes among a diversity of stakeholders (goals 5, 6, 8, and 9 of Table 5), or competencies related to becoming change agents for sustainability. Our findings stand in contrast to studies of business administration degree programmes, e.g. by Hesselbarth \& Shaltegger (2014) and Lans et al (2014), where the integration of soft skills for facilitating changes is seen as central to the design of degree programmes. Though engineers are instrumental as change agents through the designs of systems and processes, it is apparent that degree programme directors have not yet adopted learning goals that are seen as central to change agents in business administration.

One of the more surprising results - and doubtless one of those most interesting to a wider audience - were that drivers of motivation rather come from within than from regulatory documents and external audits. Table 3 clearly reveals that the programme directors are most profoundly motivated to integrate sustainability in their programmes by their own conviction of this as being an important endeavour. Also being stated as important drivers were students' attitudes and wishes together with those of their future employers. Legal requirements for higher education and audits by accreditation bodies were seen as somewhat important but rather less so than the internal drivers. Albeit surprising to us, in a way this result is rather encouraging.

Section 4.5 describes that traditional learning activities such as lectures, writing assignments and project work are dominating. However, and in contrast to this, papers highlighting good examples of sustainability education practices often emphasise innovative and active learning approaches. For example, in a study by Palme (2010), a set of 29 inspirational examples was collected throughout a range of engineering programmes at Chalmers University of Technology. The examples include peer-discussions, role plays, group work, reflective writing, and interactive lectures among others - all constituting active learning activities. In another study by Dahlin (2016), active learning in education for sustainable development through board games was shown to be more effective than traditional teaching activities. Those results were achieved in a flipped-classroom setting with board games constituting an active learning classroom activity that emphasised student reflection, interactivity and a starting point for peer-discussions and tutor-moderated discussions. The fact that innovative and active learning approaches in sustainability education seem to be lacking suggest for a potential leverage point when advocating for changes in education programmes: to develop a broader understanding and a wider reach for such approaches.

Lastly, it is interesting to observe the large discrepancy between the support programme directors receive versus the support they would like to receive from their department (Section 4.7). Interestingly, faculty training was mentioned as the most important (MSc) or second to most important (BSc) factor but was also the one that demonstrated the largest discrepancy 
between the stated need and the perceived support. This is clearly a leverage point were HEIs would be able to provide support by implementing certain policy measures and financial support. This adds to the findings by Leal Filho et al (2017) where they identified management support as the most critical obstacle, and training was only seen as moderately important. One interpretation of our results might be that there are already legally binding learning goals for all the degree programmes targeted in the study, and the motivation to work with these issues is usually internally driven. Therefore, it is not so much an issue of finding motivation as practical means of implementation. Although there is still a discrepancy between the faculty goals set and those directors would like to see, they are more interested in support on training and economic support for development efforts. Likewise, the perceived lack of teaching material is also stated as an important factor and, as with the lack of faculty training, this should be fairly straightforward to change with simple measures. Both of those factors indicate that there is a widespread confusion about how to implement sustainability in education and although there exists proper competence to train faculty and to provide teaching material, such competence is not widespread. Our interpretation is that there might be a need for more national intervention and support since HEIs not always seem to be capable of providing the proper support to their programme directors.

\section{Conclusions}

The main driver for programme directors to strengthening the element of sustainability are not the fact that this is a requirement for the right to award degrees in engineering - by law (Svensk författningssamling, 2005) as well as by accreditation regulations (Svensk författningssamling, 2006) - but rather that individual programme directors believe this to be important. It is the personal motivations of faculty and programme directors, together with the dedication from their students, that drives most of the changes currently sweeping the sector. However, further support from the department and university management is clearly needed.

The predominant learning objectives and approaches to integrating sustainability in curricula are those that could be considered rather straightforward. Most programme directors address climate change and strategies for sustainable energy. Learning objectives that reflect on the professional role and responsibilities associated with being an engineer are quite widespread. Although it is by no means simple to integrate the aforementioned objectives successfully, they could still be considered straightforward. More complex learning objectives, such as systems thinking and the ability to perceive other values and perspectives - which relate more to the interdisciplinary, complex, value-related nature of sustainability challenges - are much more rarely integrated in the programmes according to the programme directors' responses.

It is also interesting to note the dissonance between programme learning objectives and the activities to achieve those objectives. Deep integration of sustainability into the core subjects appears to be lacking, since the progression of sustainability through each programme is often weak. In addition, programme directors claim that they aim to ensure students are able to engage in interdisciplinary work but fail to give students the experience of collaborating over disciplinary boundaries. From the free text answers, however, there is a lot of additional information about work in progress. There seem to be a lot of new initiatives going on, and many of those may not have been implemented in the actual programmes yet.

Programme directors generally receive less support from their department than they would like. All kinds of support are considered important, possibly with some exceptions for economic support. The most important resources they are asking for are faculty training, 
efficient learning materials and a commitment from their university to integrate sustainabilityrelated learning objectives for all students. Degree programme managers in engineering have strong internal motivation to ensure that their graduates are able to take on the world's pressing challenges. Legally binding requirements may be helpful but not necessarily the most important. Programme directors want to educate the change agents that the World needs, but generally feel they lack university management support. University management needs to take their responsibilities for providing support seriously, to remove the barriers for change and truly promote learning for a sustainable development.

It is important to analyse programme directors' perspectives on the challenges and motives for integrating sustainability in education programmes, as they are important stakeholders. With this study, such an analysis has been performed for the subset of programme directors involved in one specific discipline (engineering education) and in one specific country (Sweden). However, the challenges and motives for making these changes in this particular subset of education programmes within HE, are not necessarily unique to the subset. Rather, the results are expected to be of interest to a broader audience. It would be highly interesting to see a report from studies that ask these questions from a broader perspective, which would necessarily be a much larger study. The authors therefore suggest a future study that would embark on such a survey, covering a broad representation of disciplines from a broad representation of national contexts.

\section{References}

Accreditation Board for Engineering Technology, Inc. (ABET). (2010). "Criteria for accrediting engineering programs: Effective for evaluations during the 2010-2011 accreditation cycle", ABET, Baltimore, USA.

Armstrong P.J. (2007). "The CDIO Syllabus: Learning Outcomes for Engineering Education", in Crawley, F. et al (Ed.), Rethinking Engineering Education: The CDIO Approach, Springer, Boston, MA, USA, pp. 45-76.

Ashford, N. A. (2004), "Major challenges to engineering education for sustainable development: What has to change to make it creative, effective, and acceptable to the established disciplines?", International Journal of Sustainability in Higher Education, Vol. 5 No. 3, pp. 239-250.

Barth, M. and Rieckmann, M. (2012), “Academic staff development as a catalyst for curriculum change towards education for sustainable development: an output perspective", Journal of Cleaner Production, Vol. 26, pp. 28-36.

Barth, M. (2015) Implementing Sustainability in Higher Education - Learning in an age of transformation. Routledge Studies in Sustainable Development, Routledge, London.

Brandt, P. et al, (2013). "A review of transdisciplinary research in sustainability science". Ecological Economics, Vol. 92, pp. 1-15.

Brundtland, G. (1987). "Report of the World Commission on Environment and Development: Our Common Future”. United Nations General Assembly document A/42/427.

Cotton, D. R. E., Warren, M. F., Maiboroda, O., and Bailey, I. (2007). "Sustainable development, higher education and pedagogy: a study of lecturers' beliefs and attitudes", Environmental Education Research, Vol. 13 No 5, pp. 579-597. 
Dlouhá, J., Glavic, P., and Barton, A. (2017). "Higher education in central european countries - critical factors for sustainability transition". Journal of Cleaner Production, Vol. 151, pp. $670-684$.

Dahlin J.-E. (2016), "The merit of educational games in sustainability education", paper presented at the 8th International Conference on Engineering Education for Sustainable Development, 4-7 September 2016, Bruges, Belgium, available at:

https://instituutvoorduurzameontwikkeling.be/fileadmin/user upload/eesd2016 proceedings.p $\underline{\mathrm{df}}$

European Network for Accreditation of Engineering Education, ENAEE (2008). "EUR-ACE framework standards for the accreditation of engineering programmes". Available at: https://www.enaee.eu/eur-ace-system/ (accessed 3 April 2020)

Enelund M., Knutson Wedel M., Lundqvist U. and Malmqvist J. (2015), "Integration of Education for Sustainable Development in the Mechanical Engineering Curriculum", Australasian Journal of Engineering Education, Vol. 19 No. 1, pp. 51-62.

Leal Filho, W., Wu, Y.-C. J., Brandli, L. L., Avila, L. V., Azeiteiro, U. M., Caeiro, S., and da Rosa Gama Madruga, L. R. (2017), "Identifying and overcoming obstacles to the implementation of sustainable development at universities", Journal of Integrative Environmental Sciences, Vol. 14 No. 1, pp. 93-108.

Hesselbarth, C. and Schaltegger, S. (2014). "Educating change agents for sustainabilitylearnings from the first sustainability management master of business administration", Journal of Cleaner Production, Vol. 62, pp. 24-36.

Kioupi, V. \& Voulvoulis, N. (2019), "Education for Sustainable Development: A Systemic Framework for Connecting the SDGs to Educational Outcomes", Sustainability, Vol. 11 No. 6104

Lang, D. J., Wiek, A., Bergmann, M., Stauffacher, M., Martens, P., Moll, P., Swilling, M., and Thomas, C. J. (2012). "Transdisciplinary research in sustainability science: practice, principles, and challenges", Sustainability Science, Vol. 7 No. 1, pp. 25-43.

Lans, T., Blok, V., and Wesselink, R. (2014). "Learning apart and together: towards an integrated competence framework for sustainable entrepreneurship in higher education", Journal of Cleaner Production, Vol. 62, pp. 37-47.

Lozano, R., Ceulemans, K., Alonso-Almeida, M., Huisingh, D., Lozano, F. J., Waas, T., Lambrechts, W., Lukman, R., and Hugé, J. (2015), “A review of commitment and implementation of sustainable development in higher education: results from a worldwide survey", Journal of Cleaner Production, Vol. 108, pp. 1-18.

Mulder, K. F. (2017), "Strategic competences for concrete action towards sustainability: An oxymoron? Engineering education for a sustainable future", Renewable and Sustainable Energy Reviews, Vol. 68 No. 2, pp. 1106-1111.

Neumayer, E. (2003), Weak versus strong sustainability: exploring the limits of two opposing paradigms, Edward Elgar Publishing, Cheltenham, UK. 
Nguyen, D. Q. (1998), "The essential skills and attributes of an engineer: A comparative study of academics, industry personnel and engineering students", Global Journal of Engineering Education, Vol. 2 No. 1, 65-75.

O'Brien, K. et al (2013), "You say you want a revolution? Transforming education and capacity building in response to global change”, Environmental Science \& Policy, Vol. 28, pp. 48-59.

Roorda, N. and Martens, P. (2008), "Assessment and certification of higher education for sustainable development”, Sustainability, Vol. 1 No. 1, pp. 41-56.

Palme U. (2010), "Good examples of education for sustainable development at Chalmers: achievements and limitations", paper presented at the 5th International Conference on Engineering Education for Sustainable Development, 19-23 September 2010, Gothenburg, Sweden.

Segalàs, J., Ferrer-Balas, D., Svanström, M., Lundqvist, U., and Mulder, K. F. (2009), "What has to be learnt for sustainability? A comparison of bachelor engineering education competences at three European universities", Sustainability Science, Vol. 4, pp. 17-27.

Sheehan M. (2014), "Designing Sustainability Curricula: A Case Following Chemical Engineering Curriculum Redesign", in Thomas, K. D., and Muga, H. E. (Eds.), Handbook of Research on Pedagogical Innovations for sustainable Development, IGI Global, Hershey, PA, USA, pp. 474-493.

Svensk författningssamling (2005), Swedish Higher Education Act (1992: 1434); changed in 2005: SFS ordinance (2005:1208).

Svensk författningssamling (2006), Swedish Higher Education Act (1993: 100); changed in 2006: SFS ordinance (2006:1053).

United Nations General Assembly (2015), Transforming our world: the 2030 Agenda for Sustainable Development, A/RES/70/1, available at: https://undocs.org/a/res/70/1

Universitetskanslersämbetet, UKÄ (2017), Universitets och högskolors arbete med att främja en hållbar utveckling: En tematisk utvärdering, del 1, Universitetskanslersämbetet, Stockholm, Sweden.

Weiss, M. and Barth, M. (2019). "Global research landscape of sustainability curricula implementation in higher education". International Journal of Sustainability in Higher Education, Vol. 20 No. 4, pp. 570-589.

Wiek, A., Withycombe, L., and Redman, C. (2011), "Key competencies in sustainability: a reference framework for academic program development", Sustainability Science, Vol. 6 No 2, pp. 203-218.

Yarime, M. and Tanaka, Y. (2012), "The issues and methodologies in sustainability assessment tools for higher education institutions - a review of recent trends and future challenges", Journal of Education for Sustainable Development, Vol. 6 No. 1, pp. 63-77. 
Ola Leifler holds a PhD in computer science. He is active in international research on sustainable software design and works with teacher training for learning for a sustainable development. He has worked with education for sustainable development in various networks in Sweden as his main professional focus for the last 6 years.

Jon-Erik Dahlin holds a PhD in fusion plasma physics and has devoted his professional life to education for sustainable development (ESD). He has taken a leading role in the integration of sustainability across programmes as a former university lecturer at the Royal Institute of Technology in Stockholm, and is now working internationally with teacher training and in an advisory capacity within ESD. 